\title{
Do Central City Promote Economic Growth of Peripheral City? Evidence from Urban Agglomeration in China
}

\author{
Ziqian Wu \\ College of Economics, Jinan University, Guangzhou, China \\ Email: ziqianwu_jnu@163.com
}

How to cite this paper: Wu, Z.Q. (2018) Do Central City Promote Economic Growth of Peripheral City? Evidence from Urban Agglomeration in China. Open Journal of Social Sciences, 6, 120-132. https://doi.org/10.4236/jss.2018.65010

Received: April 18, 2018

Accepted: May 15, 2018

Published: May 18, 2018

Copyright $\odot 2018$ by author and Scientific Research Publishing Inc. This work is licensed under the Creative Commons Attribution International License (CC BY 4.0).

http://creativecommons.org/licenses/by/4.0/

\begin{abstract}
This paper empirically studies the effect of central city economic growth on the peripheral city economic growth in urban agglomeration. Using the panel data of 120 Chinese cities from 2000 to 2012, we find that the central city economic growth significantly and substantially increases the peripheral city economic growth. These findings not only enrich the relative researches on Chinese urban agglomeration, but also strengthen the understanding of the key role of the central city under the background of promoting urbanization in China.
\end{abstract}

\section{Keywords}

Central City, Peripheral City, Economic Growth, Urban Agglomeration

\section{Introduction}

In recent years, with the acceleration of China's urbanization process, the topic of promoting the development of urban agglomerations has received increasing attention. In the Eleventh Five-Year Plan and the Twelfth Five-Year Plan, the central government has successively proposed that "the urban agglomerations should be one of the main forms of urbanization" and "rely on big cities and focus on small and medium sized cities, gradually forming the urban agglomerations which have strong economic radiation effect. In the National New Urbanization Plan (2014-2020), it also emphasized the development of urban agglomerations with high agglomeration efficiency and strong functional complementarity.

Urban agglomeration is a highly developed spatial form of integrated cities. It occurs when the relationships among cities shift from mainly competition to 
both competition and cooperation (Fang and Yu, 2017 [1]). The concept of urban agglomerations is increasingly appearing in the regional development documents which are drafted by the policymakers. This reflects two things. On one hand, the traditional provincial divisions and administrative districts economy divided by administrative boundaries is gradually shifting towards urban agglomeration economy (Zhang, 2013 [2]). On the other hand, it is more important to show the general pattern of urbanization under the background of globalization. That is, the spatial distribution of economic activities is highly concentrated in the urban agglomeration. Different cities make use of the comparative advantages through division and cooperation. The original agglomeration effect and positive spatial externalities have been further strengthened, so that the overall benefits of urban agglomerations have been qualitatively improved. Thus it can be seen that the unique advantage of urban agglomeration economy theoretically is derived from the agglomeration effect and positive spatial externalities mentioned above and the central city, which is the core region of economic and social activities within urban agglomerations, is an important carrier to exploit these two advantages. However, there are still many debates on the current status and direction of the development of the central city. There is a popular view which argues that the size of the central cities is too large and the degree of agglomeration of central cites is too high, therefore, it is necessary to limit the development of central cities (Xiao, 2009 [3]; Qin, 2008 [4]). Respect to the question about whether the city size of central cites is too large, the existing research has given a negative answer that the central cities have not reached the optimal scale (Au and Henderson, 2006 [5]) and the reason is that the central cities still face a series of institutional constraints in the process of development. On one hand, the household registration system restricts the labor shifting to the central cities. On the other hand, the allocation of central city construction land indexes has also been constrained by the state. Thus, if the existing system barriers are eliminated, the central city still has considerable space and potential to improve its size and agglomeration level. With the agglomeration effect of central cities further intensified, it is obvious that the economic growth of the central city may also have an economic radiation effect on the economic growth of neighboring peripheral cities. Is this radiation effect positive or negative? How does it work? These issues still lack the relevant empirical researches. In this paper, we try to answer the questions above.

This paper exploits the panel data of prefecture-level cities in China from 2000 to 2012, using two-way fixed effects regression model to empirically examine how the economic growth of the central city within the urban agglomeration affects the economic growth of the peripheral cities. We find that the economic growth of the central city has a significant positive radiation effect on the economic growth of peripheral cities and this effect has weakened with the extension of geographical radius. The basic conclusion is still valid after a series of robustness tests. The marginal contribution of this paper lies in: it enriches the 
research on urban agglomerations in the field of economics and gives empirical evidence for the radiation effects of the central city within urban agglomerations on peripheral cities. The empirical results of this paper also provide a possible answer for the question about whether giving priority to the development of large cities or small and medium-sized cities. The development of small and medium-sized cities must actually rely on the development of large cities and take advantage of the external radiation function of large cities to promote the economic growth and upgrade the industrial structure.

The remaining parts of this paper are organized as follows: the second part reviews the relevant literature; the third part proposes the theoretical hypothesis; the fourth part is the empirical strategy and data sources; the fifth part gives the basic empirical results; finally, it is the conclusion and policy implications.

\section{Literature Review}

The source of urban economic growth has always been one of the most concerned topics in the field of economics. A number of studies have already explained the driving forces behind urban economic growth from the perspective of traditional factors of economic growth. These factors include physical capital (Xu and Shu, 2004 [6]; Zhou and Zhang, 2008 [7]), human capital (Fleisher et al., 2010 [8]; Liang and Lu, 2015 [9]), political issues (Yao and Zhang, 2013 [10]; Luo et al., 2015 [11]) and so on. However, one of the obvious drawbacks in these studies is that they ignore the importance of space for urban development. At present, the spatial distribution of economic activities is unbalance. An important phenomenon is that more than half of global production activities are concentrated within large cities (World Bank, 2009 [12]).

To understand the impact of space on urban economic growth, the first question to answer is: Why are economic activities concentrated within cities? For this issue, some scholars try to give answers based on the geographical determinism perspective. They believe that location conditions, climate and other geographical factors have important influence on regional economic and industrial development (Goldstein and Moses 1975 [13]; Kim, 1999 [14]; Gabaix, 1999 [15]; Sachs, 2001 [16]). New Economic Geography explains the phenomenon of urban economic agglomeration from the perspective of urban scale effect. The theory holds that there are three mechanisms that allow the scale effect of cities to be exerted. They are sharing, matching and learning. In particular, due to the expansion of market scope, manufacturers have more access to inputs in cities, which reduces the cost of production and takes advantage of economies of scale. What's more, matchings between companies and labor become easier, so it reduces the searching costs of both sides. Also, the speed of knowledge diffusion is faster, which facilitates mutual learning among different groups.

Cities do not isolate from the others. The development of agglomeration economy has enabled cities with similar geographical locations to gradually form urban agglomerations around some certain core cities. The formation and de- 
velopment of urban agglomerations is driven by the economic forces and this economic power is essentially consistent with the local market effect and the congestion effect mentioned in the core-periphery theory of New Economic Geography. According to the core-periphery theory, under the interaction between the two effects, the market potential of a city will show a cubic curve pattern as the distance of this city to the central city of the region increases in a single central urban system. In other words, as the distance of the peripheral city to the central city increases, the market potential of the peripheral city will drop first. When both cities reach at a certain distance, the market potential will gradually increase. However, as the distance continues to increase, the regional market potential will decline in the end (Fujita and Krugman, 1995 [17]). Based on the core-periphery theory, some scholars have taken Chinese urban system as the research object and tried to provide some empirical evidence respect to the theory. Xu et al. (2010) [18] found that there was a cubic curve relationship between the economic growth of cities and the geographical distance to the major ports in China, that is, as the distance from cities to major ports increases, the economic growth of the city will decrease first and then increase but decline ultimately. Lu and Xiang (2012) [19] examined the impact of geographical distance between large ports and regional core cities on the secondary and tertiary industries of the peripheral city and found that a cubic curve between the geographic distance from ports and labor productivity in the tertiary industry which means that the farther away from the major ports, the productivity declines at first, then increase and decline again at last. They further found that regional big cities have more significant influence on the labor productivity of tertiary industry of their surrounding cities than on that of the secondary industry.

Recently, some scholars have begun to discuss the impact of urban agglomeration on regional economic growth and industrial structure. Wu and Liu (2008) [20] took 16 cities in the Yangtze River Delta as samples to empirically test the relationship between urbanization rate and economic growth and found that the urbanization rate significantly promoted urban economic growth. They stressed that the mechanisms behind the results were factor mobility and local investment. Yu and Wang (2011) [21] made use of the regression discontinuity method to examine the mechanism and path of economic development in the three major metropolitan regions in China, taking cities and counties of Beijing-Tianjin-Hebei Delta, Yangtze River Delta and Pearl River Delta from 2003 to 2007 as samples. They found that the overall economic performance of the metropolitan regions was driven by the Tiebout Selection mechanism and the acceleration of the urbanization process. Yuan (2016) [22] examined the impact of urban agglomerations on urban economic growth and the mechanisms by constructing indicators for measuring the extent of urban agglomerations. He found that the increase in the degree of urban agglomerations promoted the economic growth of the city and this urban agglomeration growth effect would be strengthened by weakening the negative externalities of large ci- 
ties, optimizing the industrial structure of the city and reducing the market segmentation.

A few scholars also discussed the issue of the division of labor within the urban agglomeration. Wei (2007) [23] examined the convergence of industrial structure within the metropolitan region of China and proposed that the government should actively promote the integration of new types of industrial division in the process of regional competition and cooperation. Bai and Zhao (2012) [24] used the spatial function division index for the first time to examine the functional division level among urban agglomerations in China. They found that during the sample period of 2003-2010, the overall level of labor division of urban agglomerations in China was relatively low and the division of labor in eastern urban agglomerations was higher than that in the midwest. They further found that the gap between the two regions continued to expand and the functional division of the core cities within the urban agglomerations was higher than that of the peripheral cities, but the division level of the core cities themselves was declining.

The literature has consistently verified that the development of urban agglomerations will have an impact on urban economic growth. Optimizing the industrial structure of cities within urban agglomerations and accelerating the process of regional integration are essential for exerting the advantages of urban agglomerations. However, respect to the empirical literature on Chinese urban agglomeration at present, only a few researches are based on the core-periphery theory of New Economic Geography to study the radiation range of urban agglomerations. The literature only takes the port cities into consideration and did not consider other non-portal core cities.

\section{Theoretical Hypothesis}

A number of literatures have examined the impact of the development of urban agglomeration on urban economic performance by measuring the degree of urban agglomerations and analyzed the internal mechanisms from the perspective of transport infrastructure, industrial structure and regional integration (Portnov, 2006 [25]; Portnov and Schawartz, 2009 [26]). While some literatures have examined that the impact of geographical distance on the urban economic growth and industrial structure based on the core-periphery theory of New Economic Geography and tried to give an explanation from a possible perspective (Jin et al., 2006 [27]; Meng and Lu, 2011 [28]). The previous series of literatures mainly focus on the impact of the overall degree of agglomeration on urban economic growth and the basic conclusion of these literatures is that the increase in the degree of urban agglomerations contributes to the promotion of urban economic growth and this effect is heterogeneous in regions. The effect of economic growth in regions with low levels of agglomeration is stronger than in regions with higher levels of agglomeration. However, these literatures lack in-depth research on the role of the economic growth of central cities within ur- 
ban agglomerations and how they affect the economic growth of peripheral cities. In contrast, the latter series of literatures mainly focus on the impact of the geographical distance to the central city on the economic growth and industrial development of the peripheral cities. This part of the literatures empirically found that there is cubic curve relationship between the distance to the central city and the economic growth and industry development of a city which also provides empirical evidence for the core-periphery model taking Chinese urban system as an example. However, it is worth noting that these studies only attached importance on the relatively mature urban agglomerations such as Beijing-Tianjin-Hebei Delta, Yangtze River Delta and Pearl River Delta and did not pay attention to any emerging urban agglomerations.

Due to lack comprehensive empirical studies on urban agglomerations, this paper tries to examine the impact of the economic growth of the central cities on the economic growth of peripheral cities within the top ten urban agglomerations in China. The reason why we take the central and peripheral cities within the urban agglomeration as the research unit is that respect to the current spatial distribution of economic agglomeration in China, economic activities are mainly concentrated in the central cities and other urban areas surrounding the central cities and the provincial economy divided by administrative boundaries has gradually transformed into urban agglomeration economy.

We believe that the economic growth of central cities will promote the economic growth of peripheral cities within urban agglomerations. The main reason stems from the following logic. From the perspective of the development of urban agglomerations, the relationship between central cities and peripheral cities is essentially faced with two kinds of forces, namely agglomeration effect and radiation effect. On one hand, due to the huge market size of the central city, the scale effect will enable producers to acquire inputs from a wider range of sources and reduce the production costs. At the same time, enterprises and labor will be able to get a more appropriate matching and the speed of knowledge diffusion will also become more rapid, so various factors of production will tend to shift to the central city, the economic growth of the central city will be faster than the peripheral cities. Driven by the economies of scale and agglomeration effects, the central city has become the center of factor allocation, industrial transformation and technological innovation in the region. What's more, it is important that the external radiation effect of central cities has begun to exert. The reason is that the central city has certain advantages in terms of labor productivity, technology and information compared with the peripheral cities. The central city makes use of different channels, such as the labor shifting, the division in the industry and the spread of knowledge and technology. In particular, from the perspective of the industrial structure, the radiation effect may be exerted through the development of the secondary industry in the central city. The reason is that China is currently in the stage of economic agglomeration and industrial structure transformation. Although the tertiary industry is showing a trend of rapid develop- 
ment, the secondary industry still occupies a large proportion in the national economy. The contribution of secondary industry to economic growth is still very obvious. Therefore, under the background of industrial structure transformation, the optimization and development of the secondary industry by the central city will not only contribute to further enhance the level of its own economic development but also enable the peripheral cities to develop their associated industries based on the comparative advantages. As a result, it promotes the economic growth of the peripheral cities. In summary, we propose the following theoretical hypothesis.

Hypothesis: Ceteris paribus, the economic growth of the central city will promote the economic growth of the peripheral cities.

\section{Date and Model Design}

\subsection{Data}

The data of 120 cities in top ten urban agglomerations of China from 2000-2012 is collected from different statistical yearbooks. We only use the data for the years 2000-2012 mainly because the data of the statistical yearbook was only updated to 2015 and the data of 2013 has some obvious mistakes. The data of city level variables including nominal GDP per capita, nominal GDP, total population, the rate of investment, the rate of population growth come from China City Statistical Yearbook. The GDP deflator is calculated by China Statistical Yearbook. The geographic distance of cities is calculated by ArcGIS 10.2 based on map data provided by the National Basic Geographic Information System.

\subsection{Indicator Construction}

Urban economic growth will be affected by a number of economic and social factors. In this paper, we concerned about the relationship between economic growth of peripheral cities and the economic spillover effect of central cities. In order to examine this relationship, we first construct a variable that measures the degree of the radiation effect of the central city.

$$
\text { distance }_{i t}=\frac{\ln r p g d p_{-} c_{j t}}{\ln d i s_{i j}}
$$

In Equation (1), the subscript $i, j$ and $t$ denotes the peripheral city, the central city and the year respectively. The variable $\ln r p g d p_{-} c$ represents the logarithm of the real GDP per capita of the central city $j$ in year $t$. The variable lndis represents the geographical distance between the central city $j$ and the peripheral city $i$.

\subsection{Model Design}

In order to test whether the economic growth of the central city will affect the economic growth of the peripheral city, this paper construct the following regression model based on the standard economic growth model: 


$$
\begin{aligned}
\ln r p g d p_{i t} & =\beta_{0}+\beta_{1} \text { distance }_{i t}+\beta_{2} \ln r g d p_{i t-1}+\beta_{3} \ln p o p_{i t-1}+\beta_{4} \ln i n v_{i t-1} \\
& +\beta_{5} \ln \left(n_{i t-1}+\gamma_{i t-1}+\delta_{i t-1}\right)+\eta_{i}+\lambda_{t}+\varepsilon_{i t}
\end{aligned}
$$

In Equation (2), the subscript $i$ and $t$ represent city and year respectively. The explained variable $\ln r p g d p$ is the real GDP per capita of the peripheral city which is calculated by the nominal GDP per capita and the GDP deflator of the province. The core explanatory variable distance is a measure of GDP per capita in the city center with the change of the degree of geographical distance on the periphery of urban per capita GDP of influencing variables. In addition to the core explanatory variable, the empirical model also includes a set of variables that characterize city economic growth, namely, real GDP ( $r g d p)$, total population (pop), the rate of investment (inv), the rate of population growth $(n)$, the rate of capital depreciation $(\delta)$ and the rate of technical advance $(\gamma)$. In the empirical analysis, we suppose $\gamma_{i t-1}+\delta_{i t-1}=1 . \eta_{i}$ and $\lambda_{t}$ represent city and year fixed effects respectively. $\varepsilon_{i t}$ represents the random error term.

\section{Empirical Analysis}

\subsection{Baseline Results}

In order to examine the impact of the radiation effect of the central city on the economic growth of the peripheral city, we conducted a regression test based on the above empirical model. Table 1 shows the baseline regression results. In column 1, we use the OLS method without adding any control variables and the

\begin{tabular}{|c|c|c|c|c|}
\hline \multirow{2}{*}{ Variables } & OLS & OLS & $\mathrm{FE}$ & $\mathrm{FE}$ \\
\hline & (1) & (2) & (3) & (4) \\
\hline \multirow{2}{*}{ distance } & $0.9458^{* * *}$ & $-0.1373^{* * *}$ & $1.8952^{* * *}$ & $1.4991^{* * *}$ \\
\hline & $(0.073)$ & $(0.033)$ & $(0.236)$ & $(0.210)$ \\
\hline \multirow{2}{*}{ 1_lnrgdp } & & $0.8464^{\star * *}$ & & $0.4468^{* * *}$ \\
\hline & & $(0.015)$ & & $(0.085)$ \\
\hline \multirow{2}{*}{ 1_lninv } & & $0.1571^{\star * \star}$ & & $0.1587^{\star \star \star}$ \\
\hline & & $(0.030)$ & & $(0.038)$ \\
\hline \multirow{2}{*}{ 1_lnpop } & & $-0.8041^{\star * *}$ & & $-0.4491^{\star * *}$ \\
\hline & & $(0.025)$ & & $(0.070)$ \\
\hline \multirow{2}{*}{$1 \_\ln (n+\gamma+\delta)$} & & $-0.7008^{\star * *}$ & & 0.5808 \\
\hline & & $(0.251)$ & & $(0.381)$ \\
\hline City FE & $\mathrm{N}$ & $\mathrm{N}$ & $\mathrm{Y}$ & $\mathrm{Y}$ \\
\hline Year FE & $\mathrm{N}$ & $\mathrm{N}$ & $\mathrm{Y}$ & $\mathrm{Y}$ \\
\hline $\mathrm{N}$ & 655 & 600 & 655 & 600 \\
\hline $\mathrm{R}^{2}$ & 0.174 & 0.927 & 0.951 & 0.963 \\
\hline
\end{tabular}

Table 1. Baseline regression results.

a. Robust standard error in parentheses. ${ }^{\star}{ }^{* *}$, and ${ }^{* * *}$ are statistically significant at the significance levels of $10 \%, 5 \%$, and $1 \%$, respectively. 
coefficient of the core explanatory variable distance is significantly positive. In column 2, after adding a number of control variables, we find that the coefficient of the core explanatory variable distance is significantly negative at the $1 \%$ statistical level. We control the city and year fixed effects in column 3. The coefficient of the core explanatory variable distance is significantly positive at the $1 \%$ statistical level. In column 4, after adding the control variables and the city and year fixed effects, the core explanatory variable distance is still significantly positive at the $1 \%$ statistical level. The results show that under the empirical framework of standard economic growth model, the economic growth of the central city significantly stimulates the economic growth of the peripheral cities.

\subsection{Robustness Tests}

Further, we conduct several robustness tests based on the baseline regression results. First, in the previous baseline regression, we only set the geographic radius of the central city within a radius of 150 kilometers. To test whether this setting is robust, we try to extend the radiation radius of the central city to 200,250 and 300 kilometers. Table 2 shows the regression results. All of the regression models in Column 1 - 4 add the city and year fixed effects, however, the standard error of the coefficients is clustered in urban agglomeration level. In column 1, we just set the geographic radius of the central city within a radius of 150 kilometers and find that the coefficient of the core explanatory variable distance is 1.4991, statistically significant at $5 \%$ level. In column $2-4$, we limit the

Table 2. Test of different geographic radius of the central city.

\begin{tabular}{|c|c|c|c|c|}
\hline \multirow{2}{*}{ Variables } & $150 \mathrm{~km}$ & $200 \mathrm{~km}$ & $250 \mathrm{~km}$ & $300 \mathrm{~km}$ \\
\hline & (1) & (2) & (3) & (4) \\
\hline \multirow{2}{*}{ distance } & $1.4991^{* *}$ & $1.3552^{\star * *}$ & $1.1875^{\star * *}$ & $1.1932^{\star * *}$ \\
\hline & $(0.499)$ & $(0.380)$ & $(0.351)$ & $(0.328)$ \\
\hline \multirow{2}{*}{ 1_lnrgdp } & $0.4468^{\star *}$ & $0.5801^{* * *}$ & $0.6060^{\star * *}$ & $0.6642^{\star * *}$ \\
\hline & $(0.176)$ & $(0.126)$ & $(0.122)$ & $(0.128)$ \\
\hline \multirow{2}{*}{ 1_lninv } & $0.1587^{* *}$ & $0.1576^{* *}$ & $0.1322^{* *}$ & $0.0891^{\star * *}$ \\
\hline & $(0.051)$ & $(0.050)$ & $(0.043)$ & $(0.026)$ \\
\hline \multirow{2}{*}{ 1_lnpop } & $-0.4491^{\star * \star}$ & $-0.5463^{\star * *}$ & $-0.5630^{\star \star \star}$ & $-0.5817^{\star * *}$ \\
\hline & $(0.078)$ & $(0.074)$ & $(0.078)$ & $(0.088)$ \\
\hline \multirow{2}{*}{$1 \_\ln (n+\gamma+\delta)$} & 0.5808 & 0.4962 & 0.3529 & 0.2790 \\
\hline & $(0.397)$ & $(0.305)$ & $(0.280)$ & $(0.222)$ \\
\hline City FE & YES & YES & YES & YES \\
\hline Year FE & YES & YES & YES & YES \\
\hline $\mathrm{N}$ & 600 & 909 & 1134 & 1417 \\
\hline $\mathrm{R}^{2}$ & 0.963 & 0.962 & 0.961 & 0.958 \\
\hline
\end{tabular}

a. Robust standard error in parentheses. ${ }^{*}{ }^{* *}$, and ${ }^{* * *}$ are statistically significant at the significance levels of $10 \%, 5 \%$, and $1 \%$, respectively. 
radius of radiation to 200,250 , and 300 kilometers, respectively. The results show that as the radius of radiation extends, the value of the coefficient of the core explanatory variable distance decreases, but it is still significantly positive at $1 \%$ level.

In addition, the empirical strategy also has some endogenous problems. In other words, the peripheral city which the economy scale is close to the central city may reversely have an effect on the economic growth of the central city. To solve the endogeneity, we try to calculate the average GDP of the central city and the peripheral city within the sample time period, and then compare the absolute value of the two cities one by one. The peripheral city which the average GDP is more than half or two thirds of the central city will be dropped from the sample. Table 3 shows the regression results after cutting the sample. As we can see in the table, compared with the baseline regression, the magnitude of the core explanatory variable distance has decreased, but basically the coefficient is positive significant at $1 \%$ level, which indicates that the endogeneity is weak and the baseline findings are robust.

\section{Conclusions}

The development of urban agglomerations reflects space agglomeration of global economic activity. It is also an important way to accelerate the process of urbanization in China. Based on the agglomeration effect and positive spatial externalities of urban agglomerations, the economic growth of the central city within

Table 3. Test of dropping a number of samples.

\begin{tabular}{|c|c|c|c|c|}
\hline \multirow{2}{*}{ Variables } & $150 \mathrm{~km}$ & $200 \mathrm{~km}$ & $250 \mathrm{~km}$ & $300 \mathrm{~km}$ \\
\hline & (1) & (2) & (3) & (4) \\
\hline \multirow{2}{*}{ distance } & $1.3873^{* *}$ & $1.2159^{* * *}$ & $1.0837^{* *}$ & $1.0970^{* * *}$ \\
\hline & $(0.455)$ & $(0.367)$ & $(0.350)$ & $(0.311)$ \\
\hline \multirow{2}{*}{ 1_lnrgdp } & $0.5040^{* *}$ & $0.6173^{\star * *}$ & $0.6437^{* * *}$ & $0.7010^{* * *}$ \\
\hline & $(0.174)$ & $(0.120)$ & $(0.114)$ & $(0.115)$ \\
\hline \multirow{2}{*}{ 1_lninv } & $0.1395^{\star *}$ & $0.1369^{* *}$ & $0.1106^{* *}$ & $0.0720^{* * *}$ \\
\hline & $(0.047)$ & $(0.042)$ & $(0.037)$ & $(0.020)$ \\
\hline \multirow{2}{*}{ 1_lnpop } & $-0.5515^{\star * *}$ & $-0.6431^{* * *}$ & $-0.6623^{* * *}$ & $-0.6757^{\star * *}$ \\
\hline & $(0.091)$ & $(0.072)$ & $(0.066)$ & $(0.060)$ \\
\hline \multirow{2}{*}{$1 \_\ln (n+\gamma+\delta)$} & 0.6613 & 0.5177 & 0.3722 & 0.2856 \\
\hline & $(0.392)$ & $(0.296)$ & $(0.276)$ & $(0.217)$ \\
\hline City FE & YES & YES & YES & YES \\
\hline Year FE & YES & YES & YES & YES \\
\hline $\mathrm{N}$ & 588 & 885 & 1086 & 1369 \\
\hline $\mathrm{R}^{2}$ & 0.963 & 0.962 & 0.959 & 0.956 \\
\hline
\end{tabular}


urban agglomerations will have potential impact on the economic growth of peripheral cities. This paper exploits panel data of city level from 2000 to 2012 and empirically examines the influence of the economic growth of the central city on the economic growth of the peripheral cities within the urban agglomerations using the two-way fixed effects regression model. The study indicates that the economic growth of the central city has a significant positive effect on the economic growth of peripheral cities in urban agglomerations.

The findings of this paper have some policy implications. First of all, the policymakers should realize that the central city plays an important role in driving the overall economic development of urban agglomerations and coordinating regional economic integration, therefore they should further promote the agglomeration of capital, labor and other production factors to central city and improve the labor productivity of the city which will allow the central city to stimulate the economic growth and the economic structure upgrading of the peripheral cities. Secondly, it is necessary to attach great importance to the connectivity between the central city and the peripheral cities, strengthening the infrastructure construction and the provision of public services. Finally, based on the comparative advantages of cities, it is essential to reinforce the overall integration function of the core industries of the central city and lead the industries of peripheral cities in division and collaboration.

This paper also has some limitations. First, it only considers the situation of single-center city in the empirical analysis but ignores the situation of dual-center of multi-center cities. Secondly, this paper does not further explore the possible mechanisms underlying the positive radiation effect of the central city on the peripheral cities. The above limitations will become the direction of further research.

\section{References}

[1] Fang, C.L. and Yu, D.L. (2017) Urban Agglomeration: An Evolving Concept of an Emerging Phenomenon. Landscape and Urban Planning, 162, 126-136. https://doi.org/10.1016/j.landurbplan.2017.02.014

[2] Zhang, X.L. (2013) Transformation of Regional Economy and Development of Megalopolis Economy. Academic Monthly, 7, 107-112.

[3] Xiao, J.C. (2009) The Roadmap of Urbanization with China's Characteristics and Problems of Migrants Farmers. Development Research, 5, 18-21.

[4] Qin, D.J. (2008) Take the Road of Urbanization with Chinese Characteristics and Give Full Play to the Role of Small Towns. Studies on the Socialism with Chinese Characteristics, 3, 96-99.

[5] Au, C.C. and Henderson, J.V. (2004) Are Chinese Cities Too Small? The Review of Economic Studies, 3, 549-576.

[6] Xu, X.X. and Shu, Y. (2004) Growth Dynamics in Chinese Provinces (1978-1998). China Economic Quarterly, 3, 619-638.

[7] Zhou, Y.A. and Zhang, Q. (2008) Financial Decentralization, Economic Growth and Fluctuations. Management World, 3, 6-15.

[8] Fleisher, B., Li, H.Z. and Zhao, M.Q. (2010) Human Capital, Economic Growth, and 
Regional Inequality in China. Journal of Development Economics, 2, 215-231. https://doi.org/10.1016/j.jdeveco.2009.01.010

[9] Liang, W.Q. and Lu, M. (2015) The Divergence of Skill Composition: Exploring the Complementarity and the Agglomeration of Labors. Comparative Economic \& Social Systems, 3, 185-197.

[10] Yao, Y. and Zhang, M.Y. (2013) Performance of Officials and the Promotion Tournament-Evidence from Chinese Cities. Economic Research Journal, 1, 137-150.

[11] Luo, D.L., She, G.M. and Chen, J. (2015) A New Re-Examination of the Relationship between Economic Performance and Local Leader Promotion: New Theory and New Evidence from City-Level Data. China Economic Quarterly, 3, 1145-1172.

[12] World Bank. (2008) World Development Report 2009: Reshaping Economic Geography.

[13] Goldstein, G.S. and Moses, L.N. (1975) Interdependence and the Location of Firms. Journal of Urban Economics, 1, 63-84. https://doi.org/10.1016/0094-1190(75)90040-6

[14] Kim, S. (1999) Regions, Resources, and Economic Geography: Sources of U.S. Regional Comparative Advantages, 1880-1987. Regional Science and Urban Economics, 1, 1-32. https://doi.org/10.1016/S0166-0462(98)00010-6

[15] Gabaix, X. (1999) Zipf 's Law for Cities: An Explanation. The Quarterly Journal of Economics, 3, 739-767. https://doi.org/10.1162/003355399556133

[16] Sachs, J.D. (2001) Tropical Underdevelopment. NBER Working Paper, No. 8119. https://doi.org/10.3386/w8119

[17] Fujita, M. and Krugman, P.R. (1995) When Is the Economy Monocentric? vonThnen and Chamberlin Unified. Regional Science and Urban Economics, 25, 505-528. https://doi.org/10.1016/0166-0462(95)02098-F

[18] Xu, Z., Chen, Z. and Lu, M. (2010) “Core-Periphery” Model of Chinese Urban System. World Economy, 7, 144-160.

[19] Lu, M. and Xiang, K.H. (2012) Geography and Service: Does Domestic Demand Disperse China’s Urban System? China Economic Quarterly, 3, 1079-1096.

[20] Wu, F.X. and Liu, Z.B. (2008) Research on the Mechanism of How City Group Drive Economic Growth-Empirical Evidences from 16 Cities of Yangtze River Delta. Economic Research Journal, 11, 126-136.

[21] Yu, J.W. and Wang, C.C. (2011) Analysis on Endogenous Mechanism of Metropolitan Area in Stimulating the Regional Economic Growth: Based on the Metropolitan Area of Jing-Jin-Ji, Yangtze River Delta and Pearl River Delta. Economic Review, 1, 69-78.

[22] Yuan, Q. (2016) Do Urban Clusters Promote the Development of Cities? World Economy, 9, 99-123.

[23] Wei, H.K. (2007) The New Industrial Division and Conflict Management in Metropolitan Region-Based on the Perspective of Industrial-Chain Division. China Industrial Economy, 2, 30-36.

[24] Zhao, Y. and Bai, Y.X. (2012) Measuring and Analyzing the Functional Specialization of Chinese Urban Agglomeration. China Industrial Economy, 11, 18-30.

[25] Portnov, B.A. (2007) Urban Clustering, Development Similarity, and Local Growth: A Case Study of Canada. European Planning Studies, 9, 1287-1314.

[26] Portnov, B.A. and Schwartz, M. (2009) Urban Clusters as Growth Foci. Journal of Regional Science, 2, 287-310. https://doi.org/10.1111/j.1467-9787.2008.00587.x 
[27] Jin, Y., Chen, Z. and Lu, M. (2006) Industry Agglomeration in China: Economic Geography, New Economic Geography and Policy. Economic Research Journal, 4, 79-89.

[28] Meng, K.Q. and Lu, M. (2011) China's City Clusters: Their Different Scopes. South China Journal of Economics, 2, 3-15. 